(c) American Dairy Science Association, 2004.

\title{
Economics of Delayed Replacement When Cow Performance is Seasonal*
}

\author{
A. de Vries \\ Department of Animal Sciences, \\ University of Florida, Gainesville 32611
}

\begin{abstract}
An optimal dairy cow culling and replacement model was developed; it included the option to delay entering heifers into the herd after cows were culled. The objective was to investigate whether leaving a slot temporarily vacant, to enter a heifer at a more favorable time of the year, could be economically advantageous when cow performance is seasonal. The goal of the optimization was therefore to maximize net return per slot per year. The model consisted of 3 modules: 1) a bioeconomic module to enter and calculate cow performance data and prices, 2) a replacement policy module based on dynamic programming to calculate optimal culling decisions for individual cows and when to enter heifers, and 3) a herd performance module based on Markov chains to calculate summary results for the herd. Results for the optimal culling policy under typical conditions in Florida showed that immediate replacement was economically advantageous throughout the year. However, for a nonoptimal culling policy, cows culled in May, June, and July would not be replaced by heifers until August. Realistic increases in seasonality or heifer prices, or lower milk prices, showed economic advantages of delayed over immediate replacement for both culling policies. The maximum advantage of delayed replacement of 486 price scenarios was $\$ 88$ per slot per year; cows that left the herd in the early summer and spring were not replaced by heifers until the late summer. Delayed replacement was economically advantageous when fixed costs and net returns per slot were low and seasonality was high, which is the case for a portion of Florida dairy producers.
\end{abstract}

Received September 23, 2003.

Accepted March 16, 2004.

Corresponding author: A. de Vries; e-mail: devries@animal.ufl.edu.

*This research was supported by the Florida Agricultural Experiment Station and a grant from the Southeast Milk, Inc. Milk CheckOff program, and it was approved for publication as Journal Series No. R-09763. This research was also a component of Multi-State Research Project NC-1119, Management Systems to Improve the Economic and Environmental Sustainability of Dairy Enterprises (Rev. NC-119).
(Key words: economics, replacement, optimization, seasonality)

Abbreviation key: DP = dynamic programming.

\section{INTRODUCTION}

The decision to replace a cow with a heifer may be complex. Many factors need to be considered such as the cow's current and future performance, the availability of replacement heifers, prices, and the producer's goals (Bascom and Young, 1998; Monti et al., 1999). Culling cows earlier or later than the optimal time reduces profitability (Dijkhuizen and Stelwagen, 1988; McCullough and DeLorenzo, 1996), but different producers may not make the same culling decisions for cows with similar characteristics in the same herd (Beaudeau et al., 1996).

To aid culling decisions, computer models have been developed that calculate the optimal time to replace a cow (e.g., Smith, 1971; Stewart et al., 1977; Ben-Ari et al., 1983; van Arendonk, 1985a; Kristensen, 1987; DeLorenzo et al., 1992; Kennedy and Stott, 1993). These models assumed that a replacement heifer was always available and immediately entered the herd when a cow left the herd. Furthermore, these models assumed that cows left the herd either for involuntary reasons (not under the producer's control and not subject to decision making by the models) or voluntary reasons (under the producer's control with timing of culling determined by the models).

Assuming immediate replacement, van Arendonk (1986) found that seasonality in cow performance and prices had large effects on the optimal replacement policy of herds in the Netherlands. DeLorenzo et al. (1992) modified van Arendonk's model to include conditions in Florida. They also found large effects of seasonality on the optimal replacement policy. In Florida, the largest fraction of heifers entered the herd in the fall at the start of the more favorable (cooler) time of the year, and a small fraction entered during the warm summer to replace the involuntary culled cows.

In situations where the performance of cows and prices is seasonal, or otherwise changes over time, it 
may be more profitable to temporarily delay entering heifers into the herd. Delayed replacement implies that a cow that has left the herd is not immediately replaced by a heifer in the same slot (a position for one cow in the herd). Delayed replacement results in a temporarily vacant slot. Entering heifers into the herd at a later time may better position their peak milk production and reproduction in the more favorable times of the year or match with more advantageous prices. Thus, the total annual net returns of the slot may be higher, despite the fact that the slot may be temporarily vacant.

Previous models did not allow for delayed replacement. DeLorenzo et al. (1992) assumed that immediate replacement was necessary to minimize fixed asset costs per cow in Florida. However, Jalvingh et al. (1994) showed that it was more profitable to leave a slot vacant until the fall if a cow was culled in the summer under Dutch conditions. Their voluntary culling policy was not necessarily optimal when delayed replacement was beneficial, because the policy assumed that immediate replacement took place. Delayed replacement could change the voluntary culling policy. Jalvingh et al. (1994) concluded that the assumption of immediate replacement is unavoidable in models that use dynamic programming (DP) to optimize culling decisions. Immediate replacement necessarily leads to a constant herd size over time.

The current study evaluates the economics of delayed replacement when cow performance is seasonal. The first objective of this study was to develop and describe an optimal culling and replacement model with the option to delay the entering of heifers into the herd after cows were culled. The second objective was to investigate how the option to delay replacement affected optimal cow culling and heifer entering decisions for various conditions in Florida.

\section{MATERIALS AND METHODS}

A computer model was developed that consisted of 3 modules. The replacement policy module calculates replacement decisions for individual cows based on the data from the bioeconomic module and a DP algorithm. The herd performance module simulates cows over time and calculates herd statistics based on data from the bioeconomic module and the calculated replacement decisions. The replacement policy module and the herd performance module were written in $\mathrm{C}++$. The bioeconomic module is a Microsoft Excel 2002 (Microsoft Corporation, Issaquah, WA) user-interface, where cow performance data, such as milk production curves, the probability of involuntary culling, pregnancy rates, and prices are entered or calculated. Its structure depends on the structure of the other 2 modules and is therefore described last.

\section{Replacement Policy Module}

The replacement policy module calculates optimal or nonoptimal culling decisions for 343,440 individual cow states. A cow state is a combination of 5 main features that characterize a cow. A cow can be in a state described by one of 15 milk production classes ( $\mathrm{i}, \mathrm{j}=1$ to 15), 12 lactations ( $\mathrm{k}=1$ to 12$), 24 \mathrm{mo}$ in lactation ( $\mathrm{mo}=$ 1 to 24), 10 mo of pregnancy (open or up to 9 mo pregnant; $\mathrm{n}=0$ to 9 ), and 12 mo of the year to include seasonality ( $\mathrm{s}=1$ to 12 ). For example, a cow can be characterized as in the 10th milk production class, second lactation, 6 mo in lactation, 2 mo pregnant, in February $(\mathrm{i}=10, \mathrm{k}=2, \mathrm{mo}=6, \mathrm{n}=2, \mathrm{~s}=2$ ). Some combinations are not possible and are therefore excluded. For example, a cow cannot be 4 mo pregnant and 2 mo in lactation. Each state is associated with specific revenues and costs from the bioeconomic module. The replacement policy module then uses a DP algorithm to calculate whether to keep or cull the cow in each state if the slot is occupied and whether to enter or delay entering a replacement heifer if the slot is vacant. Entering can occur immediately after culling or is one or more months delayed. The objective of these replacement decisions is to maximize the total net returns of the slot under steady state (equilibrium) conditions with a cow and her consecutive replacements.

The replacement policy module uses monthly time steps, commonly referred to as stages (t). Replacement decisions in each state and stage depend only on the performance in the current state and the optimal decisions in the next stage (DP's optimality principle). The DP algorithm starts with the calculation of optimal replacement decisions for each state far in the future and then moves backward in time, stage by stage, until the net returns per slot per year are stabilized. At this point the algorithm has converged and replacement decisions are independent of the arbitrary starting conditions. This method of successive approximations (value iteration) to solve DP algorithms is straightforward to implement on a computer.

To determine the optimal decision for every state in every stage, the DP algorithm calculates the future value of each possible decision and then chooses the decision with the highest future value. The future value is the maximum net revenue to be obtained until the end of the planning horizon (the total number of stages processed) under a policy of optimal decisions after the current stage. The length of the planning horizon is determined by the number of stages before the DP algo- 
rithm converges, which depends on the input data from the bioeconomic module.

The future value of immediately entering a heifer in a vacant slot in month $\mathrm{s}$ in state $\mathrm{t}\left(\mathrm{ENTER}_{\mathrm{s}, \mathrm{t}}\right)$ depends on the slot's fixed cost (FIXED), heifer purchase price (PHEIF) and calf revenues (CALF). The milk sales minus variable costs during the first month after calving $\left(\mathrm{REV}_{\mathrm{i}, \mathrm{k}, \mathrm{mo}, \mathrm{n}, \mathrm{s}}\right)$ are weighted by the probability $\left(\mathrm{pmilkh}_{\mathrm{i}}\right)$ that the heifer enters one of 15 milk production classes. Furthermore, there is a probability of involuntary culling at the end of the stage $\left(\operatorname{pinv}_{\mathrm{k}, \mathrm{mos}}\right)$, the associated loss due to involuntary culling (LOSS), a salvage value $\left(\mathrm{SELL}_{\mathrm{k}, \mathrm{mo}}\right)$, and the future value of the vacated slot in the next stage $\left(\mathrm{HV}_{\mathrm{s}+1, \mathrm{t}+1}\right)$. If the cow is not culled, the future value of the next stage $\left(\mathrm{CV}_{\mathrm{j}, \mathrm{k}, \mathrm{mo}, \mathrm{n}, \mathrm{s}+1, \mathrm{t}+1}\right)$ is weighted by the transition probability between milk production classes $\left(\right.$ pmilk $_{\mathrm{i}, \mathrm{j}}$ ). A discounting factor $(\alpha)$ can be implemented if desired. Thus:

$$
\begin{aligned}
& \text { ENTER }_{\mathrm{s}, \mathrm{t}}=- \text { FIXED }- \text { PHEIF }+ \text { CALF } \\
& +\sum_{\mathrm{i}=1}^{15}\left(\operatorname{pmilkh}_{\mathrm{i}} \times \operatorname{REV}_{\mathrm{i}, 1,1,0, \mathrm{~s}}+\left(1-\operatorname{pinv}_{1,1, \mathrm{~s}}\right)\right. \\
& \left.\times \sum_{\mathrm{j}=1}^{15} \operatorname{pmlk}_{\mathrm{i}, \mathrm{j}} \times \mathrm{CV}_{\mathrm{j}, 1,2,0, \mathrm{~s}+1, \mathrm{t}+1}\right) \times \alpha+\operatorname{pinv}_{1,1, \mathrm{~s}} \\
& \quad \times\left(-\mathrm{LOSS}+\mathrm{SELL}_{1,2}+\mathrm{HV}_{\mathrm{s}+1, \mathrm{t}+1}\right) \times \alpha .
\end{aligned}
$$

The future value of delaying the entering of a heifer in a vacant slot in stage $t\left(\mathrm{DELAY}_{\mathrm{s}, \mathrm{t}}\right)$ is the future value of the vacant slot in the next stage minus the fixed cost for the slot during the stage: DELAY $_{\mathrm{s}, \mathrm{t}}=-$ FIXED + $\mathrm{HV}_{\mathrm{s}+1, \mathrm{t}+1} \times \alpha$.

The future value of the optimal decision for the vacant slot is the maximum of these future values: $\mathrm{HV}_{\mathrm{s}, \mathrm{t}}=$ $\max \left(\mathrm{ENTER}_{\mathrm{s}, \mathrm{t}}, \mathrm{DELAY}_{\mathrm{s}, \mathrm{t}}\right)$. Thus, a heifer is only entered in month $\mathrm{s}$ in stage $\mathrm{t}$ if ENTER $_{\mathrm{s}, \mathrm{t}}>\mathrm{DELAY}_{\mathrm{s}, \mathrm{t}}$. This option was not available in previously described culling models based on DP.

The future value of keeping a cow $\left(\mathrm{KEEP}_{\mathrm{i}, \mathrm{k}, \mathrm{mo,n}, \mathrm{s}, \mathrm{t}}\right)$ that is eligible for insemination $(\mathrm{n}=0$ and $2 \leq \mathrm{mo} \leq 14)$ depends also on the cost of insemination (SERVICE) and the probability of conception ( ppreg $_{\mathrm{mo}, \mathrm{s}}$ ). It is calculated as:

$$
\begin{aligned}
& \operatorname{KEEP}_{\mathrm{i}, \mathrm{k}, \mathrm{mo}, 0, \mathrm{~s}, \mathrm{t}}=-\mathrm{FIXED}+\operatorname{REV}_{\mathrm{i}, \mathrm{k}, \mathrm{mo}, 0, \mathrm{~s}}+\text { SERVICE } \\
& +\left(\left(1-\operatorname{pinv}_{\mathrm{k}, \mathrm{mo}, \mathrm{s}}\right) \times \operatorname{ppreg}_{\mathrm{mo}, \mathrm{s}} \times \sum_{\mathrm{j}=1}^{15} \operatorname{pmlk}_{\mathrm{i}, \mathrm{j}}\right. \\
& \quad \times \mathrm{CV}_{\mathrm{j}, \mathrm{k}, \mathrm{mo}+1,1, \mathrm{~s}+1, \mathrm{t}+1}+\left(1-\operatorname{ppreg}_{\mathrm{mo}, \mathrm{s}}\right) \\
& \left.\times \sum_{\mathrm{j}=1}^{15} \operatorname{pmlk}_{\mathrm{i}, \mathrm{j}} \times \mathrm{CV}_{\mathrm{j}, \mathrm{k}, \mathrm{mo}+1,0, \mathrm{~s}+1, \mathrm{t}+1}\right) \times \alpha+\operatorname{pinv}_{\mathrm{k}, \mathrm{mo}, \mathrm{s}} \\
& \quad \times\left(-\operatorname{LOSS}+\mathrm{SELL}_{\mathrm{k}, \mathrm{mo}+1}+\mathrm{HV}_{\mathrm{s}+1, \mathrm{t}+1}\right) \times \alpha .
\end{aligned}
$$

All cows open at the start of the last month in lactation $(\mathrm{n}=0$ and $\mathrm{mo}=24)$ or the last month of pregnancy and in the 11th lactation ( $\mathrm{n}=9$ and $\mathrm{k}=11)$ are culled at the end of the stage. Their future value is calculated as:

$$
\begin{gathered}
\mathrm{KEEP}_{\mathrm{i}, \mathrm{k}, \mathrm{mo}, \mathrm{n}, \mathrm{s}, \mathrm{t}}=-\mathrm{FIXED} \\
+\operatorname{REV}_{\mathrm{i}, \mathrm{k}, \mathrm{mo}, \mathrm{n}, \mathrm{s}}+\left(\mathrm{SELL}_{\mathrm{k}, \mathrm{mo}+1}+\operatorname{HV}_{\mathrm{s}+1, \mathrm{t}+1}\right) \\
\times \alpha+\operatorname{pinv}_{\mathrm{k}, \mathrm{mo}, \mathrm{s}} \times-\operatorname{LOSS} \times \alpha .
\end{gathered}
$$

The future value of open cows not eligible for insemination ( $\mathrm{n}=0$ and $\mathrm{mo}=1$ or $15 \leq \mathrm{mo} \leq 23$ ) or cows pregnant less then 9 mo $(1 \leq n \leq 8)$ is calculated as:

$$
\begin{gathered}
\operatorname{KEEP}_{\mathrm{i}, \mathrm{k}, \mathrm{mo}, \mathrm{n}, \mathrm{s}, \mathrm{t}}=-\mathrm{FIXED}+\mathrm{REV}_{\mathrm{i}, \mathrm{k}, \mathrm{mo}, \mathrm{n}, \mathrm{s}} \\
+\left(1-\operatorname{pinv}_{\mathrm{k}, \mathrm{mo}, \mathrm{s}}\right) \times \sum_{\mathrm{j}=1}^{15} \operatorname{pmlk}_{\mathrm{i}, \mathrm{j}} \times \mathrm{CV}_{\mathrm{j}, \mathrm{k}, \mathrm{mo}+1, \mathrm{n}, \mathrm{s}+1, \mathrm{t}+1} \\
\times \alpha+\operatorname{pinv}_{\mathrm{k}, \mathrm{mo}, \mathrm{s}} \times\left(-\operatorname{LOSS}+\mathrm{SELL}_{\mathrm{k}, \mathrm{mo}+1}\right. \\
\left.+\mathrm{HV}_{\mathrm{s}+1, \mathrm{t}+1}\right) \times \alpha .
\end{gathered}
$$

For cows entering a new lactation $(k \geq 2)$, the value of the calf, which is assumed to be immediately sold, is added:

$$
\mathrm{KEEP}_{\mathrm{i}, \mathrm{k}, 1,0, \mathrm{~s}, \mathrm{t}}=\mathrm{KEEP}_{\mathrm{i}, \mathrm{k}, 1,0, \mathrm{~s}, \mathrm{t}}+\mathrm{CALF} .
$$

Pregnant cows calving at the end of the stage $(n=9)$ but not in their 11th lactation $(\mathrm{k} \leq 10)$ can enter a new lactation. Their future value is:

$$
\begin{gathered}
\operatorname{KEEP}_{\mathrm{i}, \mathrm{k}, \mathrm{mo}, 9, \mathrm{~s}, \mathrm{t}}=-\operatorname{FIXED}+\operatorname{REV}_{\mathrm{i}, \mathrm{k}, \mathrm{mo}, 9, \mathrm{~s}} \\
+\left(1-\operatorname{pinv}_{\mathrm{k}, \mathrm{mo}, \mathrm{s}}\right) \times \sum_{\mathrm{j}=1}^{15} \operatorname{pmlk}_{\mathrm{i}, \mathrm{j}} \times \mathrm{CV}_{\mathrm{j}, \mathrm{k}+1,1,0, \mathrm{~s}+1, \mathrm{t}+1} \\
\times \alpha+\operatorname{pinv}_{\mathrm{k}, \mathrm{mo}, \mathrm{s}} \times\left(-\operatorname{LOSS}+\mathrm{SELL}_{\mathrm{k}, \mathrm{mo}+1}\right. \\
\left.+\mathrm{HV}_{\mathrm{s}+1, \mathrm{t}+1}\right) \times \alpha .
\end{gathered}
$$

The future value of keeping the cow is compared with the future value of immediately voluntarily culling the cow $\left(\mathrm{CULL}_{\mathrm{i}, \mathrm{k}, \mathrm{mo}, \mathrm{n}, \mathrm{s}, \mathrm{t}}\right)$, calculated as:

$$
\mathrm{CULL}_{\mathrm{i}, \mathrm{k}, \mathrm{mo}, \mathrm{n}, \mathrm{s}, \mathrm{t}}=\mathrm{SELL}_{\mathrm{k}, \mathrm{mo}}+\mathrm{HV}_{\mathrm{s}, \mathrm{t}} .
$$

The future value of the optimal decision to keep the cow at least one more stage, vs. immediately culling her, is the maximum of these future values:

$$
\mathrm{CV}_{\mathrm{i}, \mathrm{k}, \mathrm{mo}, \mathrm{n}, \mathrm{s}, \mathrm{t}}=\max \left(\operatorname{KEEP}_{\mathrm{i}, \mathrm{k}, \mathrm{mo}, \mathrm{n}, \mathrm{s}, \mathrm{t}}, \mathrm{CULL}_{\mathrm{i}, \mathrm{k}, \mathrm{mo}, \mathrm{n}, \mathrm{s}, \mathrm{t}}\right) .
$$

The cow in this state is kept at least one more month (decision $\mathrm{u}_{\mathrm{i}, \mathrm{k}, \mathrm{mo}, \mathrm{n}, \mathrm{s}, \mathrm{t}}=1$ ) if $\mathrm{KEEP}_{\mathrm{i}, \mathrm{k}, \mathrm{mo}, \mathrm{n}, \mathrm{s}, \mathrm{t}}>\mathrm{CULL}_{\mathrm{i}, \mathrm{k}, \mathrm{mo}, \mathrm{n}, \mathrm{s}, \mathrm{t}}$. Otherwise, she is immediately culled $\left(\mathrm{u}_{\mathrm{i}, \mathrm{k}, \mathrm{mo}, \mathrm{n}, \mathrm{s}, \mathrm{t}}=0\right)$. 
The algorithm moves backwards from stage $t$ to $t-$ 1 and converges when the value $\sum_{\mathrm{s}=1}^{12}\left(\mathrm{HV}_{\mathrm{s}, \mathrm{t}}-\mathrm{HV}_{\mathrm{s}, \mathrm{t}+12}\right)$ becomes constant and thus independent of $t$. This value is equal to the herd average net return per slot per year when no discounting takes place $(\alpha=1)$.

The maximum net return per slot per year is obtained when the DP algorithm is allowed to determine all entering and voluntary culling decisions (the optimal policy). Nonoptimal policies can be simulated when one or more restrictions are placed on keeping or voluntary culling cows. The DP algorithm can still be allowed to make some decisions. For example, the option to delay replacement can be enforced or prohibited for each month of the year, whereas the DP algorithm still calculates the keep or cull decision for each state given the heifer entering restriction. To prohibit delay in month $s$ in stage $t$, set DELAY $Y_{s, t}<E^{2} T E R_{s, t}$. If delay is enforced in month s, set ENTER $\mathrm{s}_{\mathrm{s}, \mathrm{t}}<\mathrm{DELAY}_{\mathrm{s}, \mathrm{t}}$. Similarly, decisions to keep or cull cows in certain states can be user defined by setting $\mathrm{KEEP}_{\mathrm{s}, \mathrm{t}}<\mathrm{CULL}_{\mathrm{s}, \mathrm{t}}$ or vice versa. A policy in which the user defines the culling decisions for all states and the months where heifers are entered can also be simulated, but the DP algorithm then has no optimization function. Note that $s+1$ implies the next calendar month: December is followed by January.

\section{Herd Performance Module}

The herd performance module calculates herd statistics resulting from the bioeconomic data and the decisions calculated by the replacement policy. This module is modeled as a Markov chain. Markov chains and the Markov decision process were described in more detail for similar cow replacement problems by Jalvingh et al. (1992) and DeLorenzo et al. (1992). The herd performance module has the same states as the replacement policy module.

The herd performance module simulates one cow (or lack thereof) in one slot from stage to stage, weighing the probability that the cow enters a state (dependent on the decision calculated by the DP algorithm) with her performance, revenues, and costs in that state. If the Markov chain is simulated for a sufficiently long time, the state-to-state transition probabilities become stationary and the herd is in steady state. At that point the probability that a cow is in a state remains constant. The herd statistics in each stage can be calculated from the weighted performance and events in each state and stage.

The fraction of cows that enter a stage $t$ depends on the fraction of cows at the beginning of the stage $\left(\right.$ pstate $\left._{\mathrm{i}, \mathrm{k}, \mathrm{mo}, \mathrm{n}, \mathrm{s}, \mathrm{t}}\right)$ multiplied by the decision to keep cows in the stage $\left(u_{i, k, m o, n, s, t}=1\right)$. If the decision is to delay entering of heifers, then the fraction of heifers $(\mathrm{k}=1$, $\mathrm{mo}=1, \mathrm{n}=0)$ at the beginning of the stage is psta$\mathrm{te}_{\mathrm{j}, 1,1,0, \mathrm{~s}, \mathrm{t}}=0$. If the decision is to enter heifers in stage $t$, then the fraction of heifers that enters is calculated as 1 minus the fraction of cows that enter the stage:

$$
\begin{aligned}
\text { pstate }_{\mathrm{j}, 1,1,0, \mathrm{~s}, \mathrm{t}} & =1-\sum_{\mathrm{i}=1}^{15} \sum_{\mathrm{k}=1}^{12} \sum_{m o=1}^{24} \sum_{\mathrm{n}=1}^{9} \\
\text { pstate }_{\mathrm{i}, \mathrm{k}, \mathrm{mo}, \mathrm{n}, \mathrm{s}, \mathrm{t}} & \times \mathrm{u}_{\mathrm{i}, \mathrm{k}, \mathrm{mo}, \mathrm{n}, \mathrm{s}, \mathrm{t}} \times \mathrm{pmilkh}_{\mathrm{j}} \\
\text { (excluding } \mathrm{k} & =1, \mathrm{mo}=1, \mathrm{n}=0) .
\end{aligned}
$$

The fraction of heifers that enter the herd in stage $t$ is equal to $\sum_{\mathrm{j}=1}^{15}$ pstate $_{\mathrm{j}, 1,1,0, \mathrm{~s}, \mathrm{t}}$. All slots are then occupied at the beginning of stage $t$.

The fraction of cows in the states in the next stage is calculated as follows. Open cows eligible to be inseminated $(\mathrm{n}=0$ and $2 \leq \mathrm{mo} \leq 14)$ that get pregnant have transition probability: pstate $_{\mathrm{j}, \mathrm{k}, \mathrm{mo}+1,1, \mathrm{~s}+1, \mathrm{t}+1}=$ pstate $_{\mathrm{i}, \mathrm{k}, \mathrm{mo}, 0, \mathrm{~s}, \mathrm{t}} \times \mathrm{u}_{\mathrm{i}, \mathrm{k}, \mathrm{mo}, 0, \mathrm{~s}, \mathrm{t}} \times\left(1-\operatorname{pinv}_{\mathrm{k}, \mathrm{mo}, \mathrm{s}}\right) \times \operatorname{ppreg}_{\mathrm{mo}, \mathrm{s}} \times$ pmlk $_{i, j}$. Cows that don't conceive remain open: pstate $_{\mathrm{j}, \mathrm{k}, \mathrm{mo}+1,0, \mathrm{~s}+1, \mathrm{t}+1}=$ pstate $_{\mathrm{i}, \mathrm{k}, \mathrm{mo}, 0, \mathrm{~s}, \mathrm{t}} \times \mathrm{u}_{\mathrm{i}, \mathrm{k}, \mathrm{mo}, 0, \mathrm{~s}, \mathrm{t}} \times(1-$ $\left.\operatorname{pinv}_{\mathrm{k}, \mathrm{mo}, \mathrm{s}}\right) \times\left(1-\right.$ ppreg $\left._{\mathrm{mo}, \mathrm{s}}\right) \times$ pmlk $_{\mathrm{i}, \mathrm{j}}$. For open cows not eligible to be inseminated $(\mathrm{n}=0$ and $(\mathrm{mo}=1$ or $\mathrm{mo} \geq$ 15): pstate $_{\mathrm{j}, \mathrm{k}, \mathrm{mo}+1,0, \mathrm{~s}+1, \mathrm{t}+1}=$ pstate $_{\mathrm{i}, \mathrm{k}, \mathrm{mo}, 0, \mathrm{~s}, \mathrm{t}} \times \mathrm{u}_{\mathrm{i}, \mathrm{k}, \mathrm{mo}, 0, \mathrm{~s}, \mathrm{t}} \times(1$ $\left.-\operatorname{pinv}_{\mathrm{k}, \mathrm{mo}, \mathrm{s}}\right) \times \operatorname{pmlk}_{\mathrm{i}, \mathrm{j}}$. For cows pregnant less than 9 mo $(1 \leq \mathrm{n} \leq 8)$ the transition probability is: pstate $_{\mathrm{j}, \mathrm{k}, \mathrm{mo}+1, \mathrm{n}+1, \mathrm{~s}+1, \mathrm{t}+1}=$ pstate $_{\mathrm{i}, \mathrm{k}, \mathrm{mo}, \mathrm{n}, \mathrm{s}, \mathrm{t}} \times \mathrm{u}_{\mathrm{i}, \mathrm{k}, \mathrm{mo}, \mathrm{n}, \mathrm{s}, \mathrm{t}} \times(1-$ $\left.\operatorname{pinv}_{\mathrm{k}, \mathrm{mo}, \mathrm{s}}\right) \times$ pmlk $_{\mathrm{i}, \mathrm{j}}$. Finally, for cows calving at the end of the stage $(\mathrm{n}=9)$ and not in their 11th lactation $(\mathrm{k} \leq$ 10): pstate $_{\mathrm{j}, \mathrm{k}+1,1,0, \mathrm{~s}+1, \mathrm{t}+1}=$ pstate $_{\mathrm{i}, \mathrm{k}, \mathrm{mo}, \mathrm{n}, \mathrm{s}, \mathrm{t}} \times \mathrm{u}_{\mathrm{i}, \mathrm{k}, \mathrm{mo}, \mathrm{n}, \mathrm{s}, \mathrm{t}} \times(1$ $\left.-\operatorname{pinv}_{\mathrm{k}, \mathrm{mo}, \mathrm{s}}\right) \times \operatorname{pmlk}_{\mathrm{i}, \mathrm{j}}$.

Herd statistics for each stage $t$ are calculated from the performance in the state weighted by the probability that the cow is in the state. For example, average milk sales minus variable costs per slot in stage $t$ are calculated as $\sum_{\mathrm{i}=1}^{15} \sum_{\mathrm{k}=1}^{12} \sum_{m o=1}^{24} \sum_{\mathrm{n}=1}^{9}$ pstate $_{\mathrm{i}, \mathrm{k}, \mathrm{mo}, \mathrm{n}, \mathrm{s}, \mathrm{t}} \times \mathrm{u}_{\mathrm{i}, \mathrm{k}, \mathrm{mo}, \mathrm{n}, \mathrm{s}, \mathrm{t}}$ $\times \mathrm{REV}_{\mathrm{i}, \mathrm{k}, \mathrm{mo}, \mathrm{n}, \mathrm{s}}$.

\section{Bioeconomic Module}

The bioeconomic module prepares cow performance data and prices that are used in the replacement policy module and herd performance module. Default parameters were obtained from the literature or estimated to mimic typical conditions in Florida.

Milk production. No current milk production curves under Florida conditions were available. Therefore, average daily milk production by month of calving and month in lactation was estimated for first, second, and 


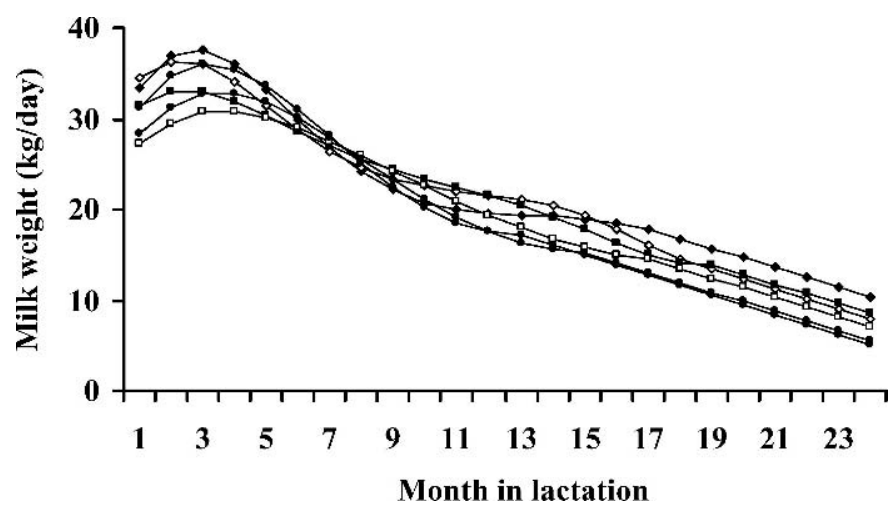

Figure 1. Second lactation milk production curves by 6 mo of calving: $\bullet$ January, $\diamond$ March, $\square$ May, $\square$ July, 0 September, $\bigcirc$ November. Months not shown follow similar seasonal patterns.

later lactations from over 2 million Florida DHI test-day records. Thirty-six fifth-order polynomials were fitted using regression to describe the seasonal production patterns in Florida, similar to DeLorenzo et al. (1992). Figure 1 shows daily milk production patterns for second-lactation cows for 6 mo of calving. Milk production patterns for first-lactation cows were less affected by the month of the year (less seasonal) and were more persistent. Milk production patterns for later lactation cows were more seasonal and less persistent. These patterns agree with the older Florida milk production patterns (DeLorenzo et al., 1992), except that the weights in the current study are higher.

For first-lactation cows, minimum daily peak milk weight was $26.8 \mathrm{~kg}$ for heifers that calved in May, and the maximum peak production was $31.0 \mathrm{~kg}$ for heifers that calved in December. For second-lactation cows, minimum and maximum peak milk weights were 30.8 and $37.6 \mathrm{~kg}$, for cows calving in July and January, respectively. For later lactation cows, corresponding peak production was 32.0 (July calvings) and $39.4 \mathrm{~kg}$ (January calvings).

Pregnancy reduced daily milk production by 5,10 , and $15 \%$ in mo 5, 6, and 7 of pregnancy based on adjustment factors estimated through regression equations by McCullough (1992). Cows were dry in mo 8 and 9 of pregnancy. Fat content of the milk was set at $3.5 \%$ to calculate DM feed intake.

The 15 milk production classes were calculated as described by van Arendonk (1985a) with the lowest class equal to $70 \%$ of the average daily milk production and the highest class equal to $130 \%$. Coefficient of variation was $12 \%$. The model allowed for monthly transitions between milk production classes, as described by Houben et al. (1994).

Body weight. Body weights for lactations one and later by month in milk and month of pregnancy were

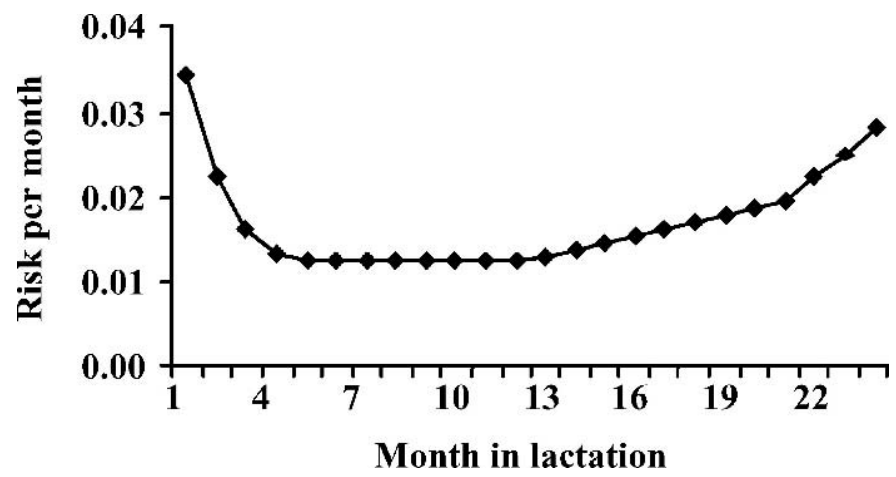

Figure 2. Average probability of involuntary culling by month in lactation.

calculated using the function described by van Arendonk (1985b) fitted on the body weight data described by the NRC (2001). These BW data were used when calculating DM feed intake and salvage values for culled cows.

Feed intake. Daily DM feed intake for lactating cows was calculated according to the NRC (2001). Dry cows had a daily DMI of $12 \mathrm{~kg}$.

Reproduction. Average pregnancy rates by month in lactation and seasonal effects were estimated from 402,866 Florida lactation records using Proc Lifereg in SAS (Allison, 1995). Average pregnancy rates declined nearly linearly from $15 \%$ at the end of second month in lactation to $10 \%$ at the end of the 15th mo. Because these estimated pregnancy rates represented the probability of pregnancy in a 21-d estrous cycle, the monthly probability of pregnancy was calculated as the pregnancy rate multiplied by 1.45 . Seasonal effects on the probability of pregnancy, expressed as odds ratios, for January through December were estimated as 1.33 , $1.34,1.28,1.19,0.91,0.71,0.62,0.63,0.67,0.82,1.03$, and 1.25. This level of seasonality in reproductive performance agrees with previous estimates (DeLorenzo et al., 1992).

Forty percent of estruses were assumed to result in an insemination to calculate the cost of breeding. The voluntary waiting period for the start of insemination efforts was 2 mo after calving.

Involuntary culling. Cows that were kept during a stage still had a chance of involuntary culling at the end of the stage. The probabilities of involuntary culling by month in lactation and lactation number were calculated from 402,866 Florida DHI lactation records using Proc Lifereg in SAS. Records of culled cows with the reasons "dairy," "low production," and "reproduction" were considered censored. The average probabilities of involuntary culling by month in lactation are shown in Figure 2. Odds ratios for lactation number increased 
Table 1. Annual results for immediate and optimal delayed replacement for the default input data per slot per year.

\begin{tabular}{|c|c|c|c|c|}
\hline \multirow[b]{2}{*}{ Variable } & \multicolumn{2}{|c|}{ Policy $\mathrm{A}^{1}$} & \multicolumn{2}{|c|}{ Policy $\mathrm{B}^{2}$} \\
\hline & $\begin{array}{l}\text { Immediate } \\
\text { replacement }\end{array}$ & $\begin{array}{l}\text { Delay } \\
\text { allowed }^{3}\end{array}$ & $\begin{array}{l}\text { Immediate } \\
\text { replacement }\end{array}$ & $\begin{array}{l}\text { Delay } \\
\text { allowed }^{4}\end{array}$ \\
\hline Net return $(\$)$ & 133 & & 74 & 75 \\
\hline Milk return (\$) & 3025 & & 2979 & 2934 \\
\hline Livestock return $(\$)$ & 297 & & 299 & 292 \\
\hline Feed cost $(\$)$ & 1423 & & 1418 & 1395 \\
\hline Heifer cost (\$) & 511 & & 539 & 523 \\
\hline Labor cost $(\$)$ & 419 & & 423 & 415 \\
\hline Other variable costs $(\$)$ & 377 & & 367 & 362 \\
\hline Fixed costs $(\$)$ & 458 & & 458 & 458 \\
\hline Milk weight (kg) & 8853 & & 8717 & 8587 \\
\hline Days to conception & 136 & & 120 & 119 \\
\hline Involuntary culling (\%) & 22.2 & & 21.9 & 22.0 \\
\hline Voluntary culling $(\%)$ & 14.4 & & 16.6 & 16.0 \\
\hline Herd life (d) & 1002 & & 950 & 963 \\
\hline Slots vacant $(\%)$ & 0 & & 0 & 1.7 \\
\hline \multicolumn{5}{|l|}{${ }^{1}$ Optimal policy. } \\
\hline \multicolumn{5}{|c|}{$\begin{array}{l}{ }^{2} \text { Nonoptimal policy: cows are inseminated up to } 8 \text { mo in lactation and voluntary culling takes place if } \\
\text { monthly milk sales are lower than feed cost, labor cost, veterinary cost, and other variable costs. } \\
{ }^{3} \text { Optimal delayed replacement is not advantageous. Results for optimal delayed replacement are the same } \\
\text { as for immediate replacement. }\end{array}$} \\
\hline
\end{tabular}

nearly linearly from 0.72 for first-lactation cows to 4.87 for ninth and later lactation cows. The effects of stage of lactation and lactation number are in agreement with results reported by Milian-Suazo et al. (1988).

Other inputs and prices. Prices were derived from various industry sources to obtain realistic returns and costs as observed in the Florida dairy industry (de Vries et al., 2003). Salvage value of culled cows was set at $\$ 0.80$ per kg body weight, excluding any weight due to pregnancy. Heifer price was $\$ 1400$. Milk price was $\$ 0.34$ per kg ( $\$ 15.50$ per $100 \mathrm{lb})$. Cost of an insemination was $\$ 15$. Calves were sold at birth at $\$ 112.50$ per head. Feed cost for lactating cows was valued at $\$ 0.23$ per kilogram of DMI. Feed cost for dry cows was $\$ 0.15$ per $\mathrm{kg}$ of DMI. Veterinary costs were $\$ 39, \$ 23$, and $\$ 8$ for the first 3 mo in lactation, respectively, and $\$ 1 /$ mo afterwards [based on Rogers et al. (1988) and adjusted for inflation]. Labor costs were $\$ 9 / \mathrm{h}$, assuming $8.2 \mathrm{~min}$ of labor per lactating cow per day and 3.4 min per dry cow per day (Houben, 1995). Direct loss due to involuntary culling was set at $\$ 350$ per case [based on Rogers et al. (1988) and adjusted for inflation]. This loss was an estimate of extra veterinary cost, a lowered salvage value, and reduced milk production just before the involuntary culling. Other variable costs per cow per day were $\$ 0.50$ if the cow was present. Fixed costs per slot per day were set at $\$ 1.25$, whether the slot was vacant or not.

Interest was set at zero for simplicity because initial results of this study using 4 and $8 \%$ annual interest showed only very minor effects of discounting on the optimal replacement policies. The negligible effects of discounting are in agreement with Kristensen (1991). Net return per slot was calculated as returns minus variable and fixed costs.

\section{Experimental Design}

Replacement policy A referred to the optimal policy for all cows (states) as determined by the DP algorithm. A nonoptimal replacement policy B was also defined. It included efforts to inseminate open cows up to 8 mo in lactation ( $240 \mathrm{~d})$ and voluntary culling of open cows if their monthly milk sales were lower than their feed, labor, veterinary, and other variable costs. Both policies $\mathrm{A}$ and $\mathrm{B}$ were evaluated with and without the option to delay entering heifers.

Sensitivity analyses were carried out by varying milk prices, heifer prices, and percentage seasonality in milk production, pregnancy rates, and involuntary culling. Seasonality was calculated as a percentage of the difference between the average for the month of the year and the annual average. Furthermore, the effect of the proportion of fixed cost in the total cost was evaluated.

\section{RESULTS}

Results are presented for the herd in steady state as calculated with the herd performance module. Annual results for the default input data are summarized in 


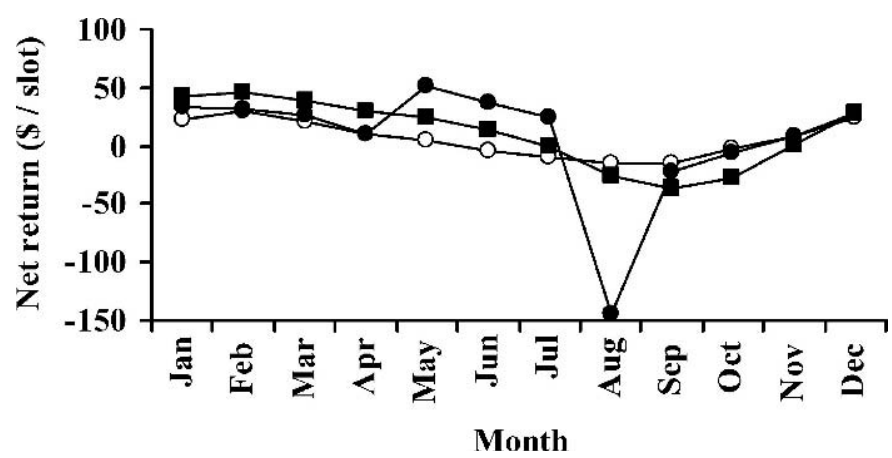

Figure 3. Net return per slot per month of the year. Policy A: immediate replacement and delay allowed are the same (ם). Policy B: immediate replacement $(\bigcirc)$ and delay allowed $(\bullet)$.

Table 1. Net return per slot per year with immediate replacement of culled cows was $\$ 133$ under policy A and $\$ 74$ under policy B. Annual fixed cost per slot was $\$ 458$.

Delayed replacement was not advantageous under policy A. Optimal delayed entering of heifers increased net returns only for policy B by $\$ 1.66$ per slot per year. The small increase for policy B showed that the default prices and seasonality in cow performance were near the point where optimal delayed replacement was advantageous over immediate replacement. Delayed replacement resulted in decreases in both returns and costs per slot per year. Annual cull rate due to delayed replacement was only $0.5 \%$ lower.

Figures 3 and 4 show the seasonality in net returns and entering heifers per month of the year for the default input data. With immediate replacement, heifers were entered in each month due to ongoing involuntary and voluntary culling. The largest percentage of heifers entered in October (5.1\%, policy A) or April (3.7\%, policy B). The fraction of heifers entering the herd was more evenly distributed over the year under policy B. Net

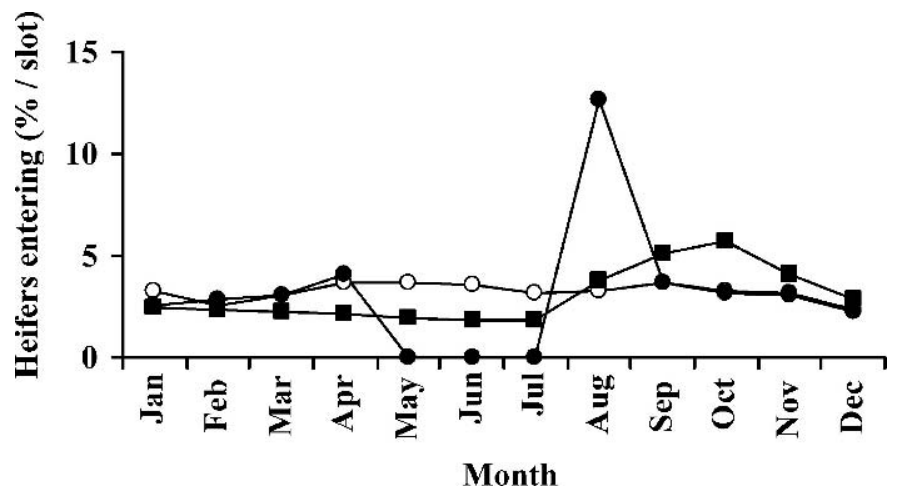

Figure 4. Heifers entering per month of the year. Policy A: immediate replacement and delay allowed are the same (四. Policy B: immediate replacement $(\bigcirc)$ and delay allowed $(\bullet)$. return was highest in winter when milk sales were high and lowest in late summer and early fall when most heifers were purchased and milk sales were still depressed by the warmer weather. Net returns were negative in July through October under policy A and in June through October under policy B.

The option to delay replacement of culled cows resulted in no heifers entering in May, June, and July under policy B. Consequently, heifer purchases were increased in August, because enough heifers were purchased to fill all slots that had become vacant due to culling in the previous months. This resulted in a large negative net return in August ( $\$ 145$ per slot). Net returns were higher in the summer months because no heifers were purchased, despite some vacant slots. In May, June, and July, respectively, 3.7, 7.1, and 9.9\% of slots under policy B were vacant.

Table 2 shows that the net returns per slot per year with immediate replacement varied from $-\$ 472$ (lowest value) to $\$ 760$ (highest value) under the most extreme combinations of milk prices, and heifer prices evaluated in this study. Net returns for other combinations of milk prices and heifer prices, in case of immediate replacement, can be estimated by linear interpolation of these extremes. As expected, net returns under the optimal policy A were higher than under policy B for every combination. More seasonality resulted in higher net returns.

The effects of variations in seasonality, milk prices, and heifer prices on the increase in net return per slot per year due to the option to delay replacement are shown in Figure 5. Delayed replacement was more likely to be advantageous with more seasonality and when average net returns were low, such as due to lower milk prices and higher heifer prices. For all 486 evaluated scenarios, the value of optimal delayed replacement over immediate replacement varied from $\$ 0$ to $\$ 88$. The largest increases in net return due to optimal delayed replacement coincided with the lowest net returns per slot in the case of immediate replacement. Figure 5 furthermore shows that delayed replacement was advantageous for a wider range of prices, and the average value was higher when cow performance was more seasonal.

Total net return per slot per year under delayed replacement is calculated from Table 2 and Figure 5. For example, the net return under delayed replacement, policy B, milk price $\$ 15.50$, heifer price $\$ 1400$, and $200 \%$ seasonality was $\$ 120+\$ 22=\$ 144$ per slot per year.

For all price-seasonality scenarios evaluated, the option to delay replacement never resulted in leaving all slots permanently vacant (an infinite delay). The lowest net return per slot per year obtained was $-\$ 446$ (policy 
Table 2. Net returns per slot per year (\$) when culled cows are immediately replaced for 2 culling policies and variations in seasonality, milk price, and heifer price.

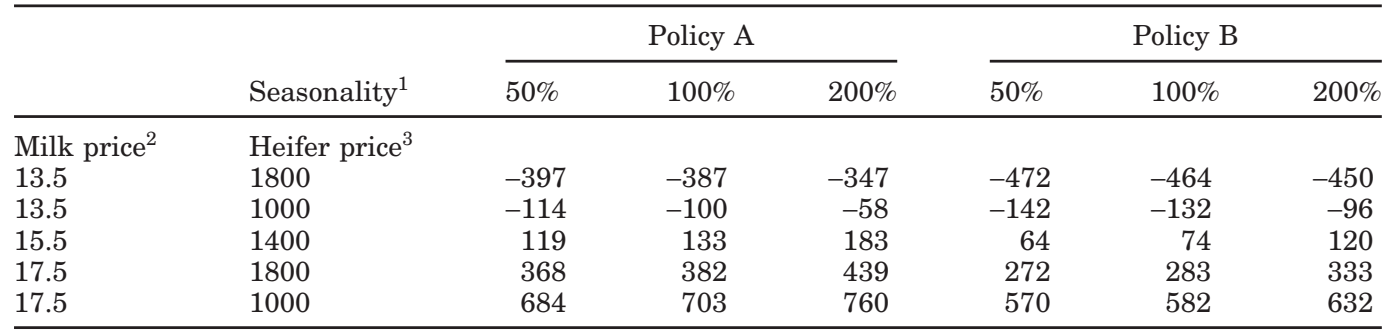

${ }^{1}$ Seasonality was calculated as a percentage of the difference between the average performance for the month of the year and the annual average.

${ }^{2}$ Milk price per $45.2 \mathrm{~kg}(\$)(13.5,15.5$, and 17.5 is $29.87,34.29$, and 38.72 per $100 \mathrm{~kg}$, respectively).

${ }^{3}$ Heifer price per head $(\$)$.
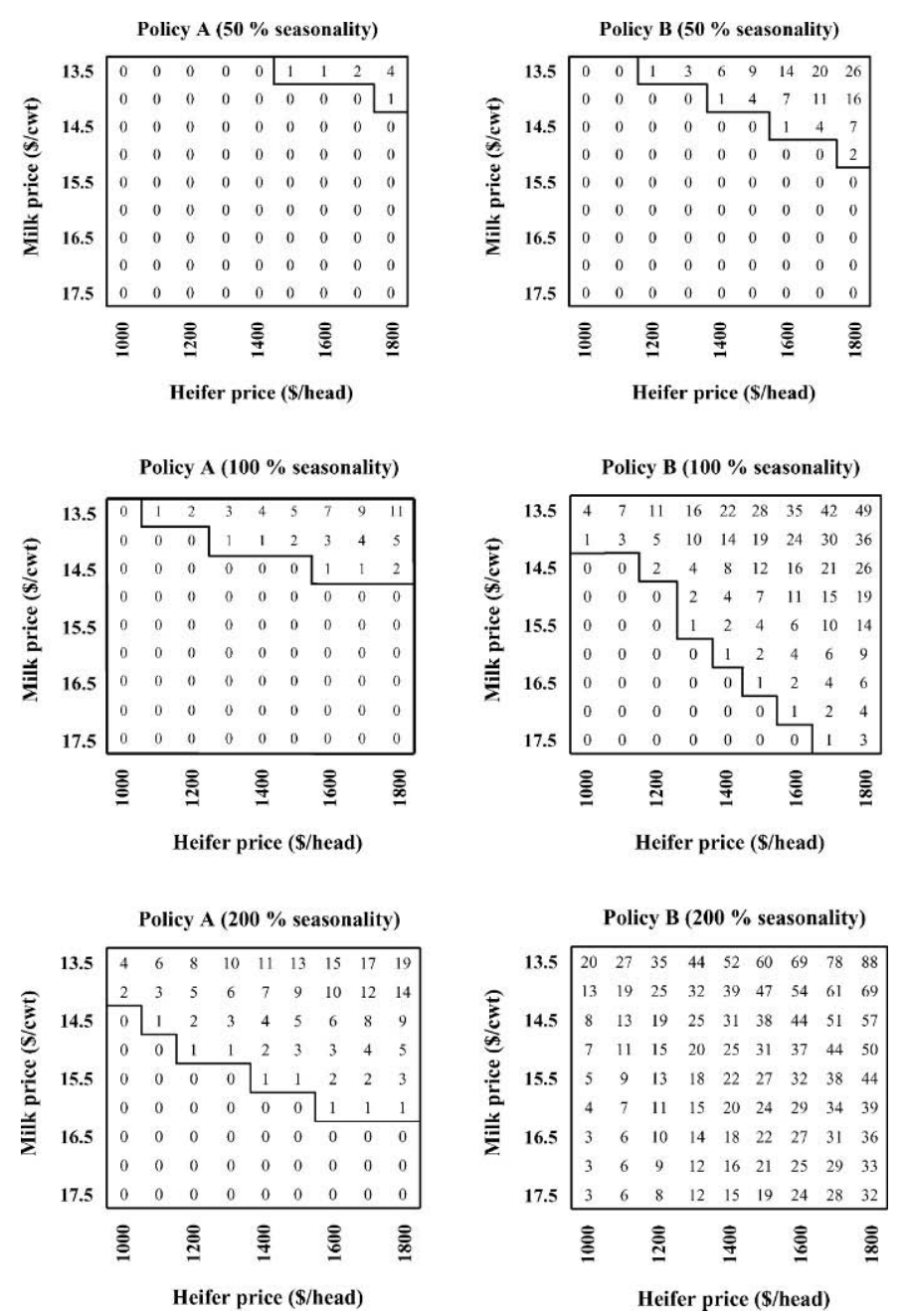

Figure 5. Increase in net return per slot per year due to optimal delayed entering of heifers compared with immediate replacement of culled cows for various combinations of seasonality in cow performance, milk prices, and heifer prices. Seasonality of cow performance was calculated as a percentage of the difference between the average for the month of the year and the annual average.
$\mathrm{B}$, milk price $\$ 13.50$, heifer price $\$ 1800$, and $50 \%$ seasonality). This was still $\$ 12$ more than the annual fixed costs of $\$ 458$. Under this scenario, heifers were only entered in October and November. Only under the default scenarios (heifer price $\$ 1400,100 \%$ seasonality) when milk prices were below $\$ 12.37$ (policy A) or $\$ 12.51$ (policy B) were all slots permanently vacant.

Figure 6 shows that of the 486 scenarios evaluated, delayed replacement was most often advantageous over immediate replacement in July (policy B) and August (policy A). If additional months of delay were advantageous, these delays occurred more in the summer and spring months than the fall and winter. Heifers were always entered in November under each scenario.

The decrease in net return due to deliberately not entering heifers in June and July, whereas immediate replacement in those months was optimal (282 of the

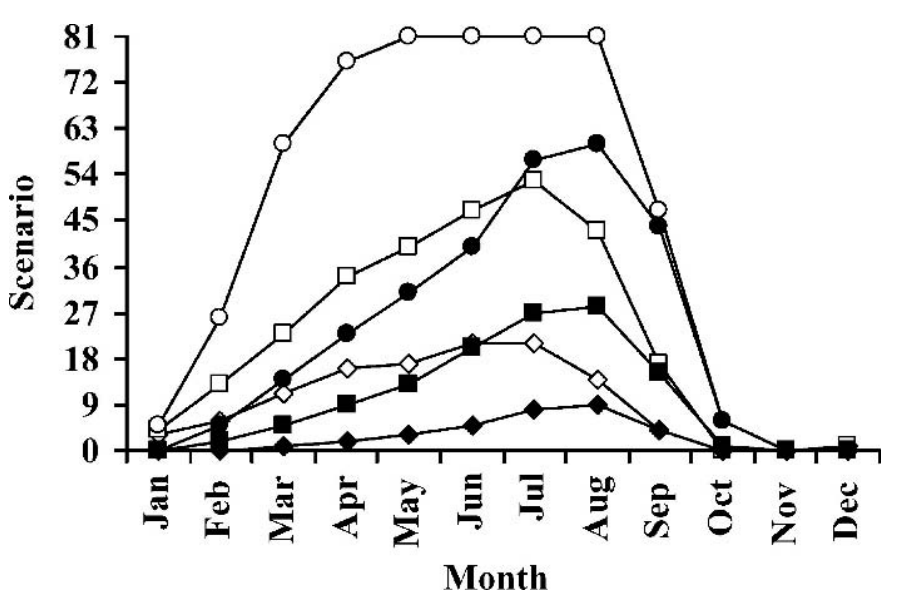

Figure 6. Number of scenarios where not entering heifers in the month was optimal (81 milk and heifer price scenarios were evaluated). Policy A (seasonality: 50\%, 100\%, 200\%), and Policy B (seasonality: $\diamond 50 \%, \square 100 \%, \bigcirc 200 \%$ ). Seasonality of cow performance was calculated as a percentage of the difference between the average for the month of the year and the annual average. 
Table 3. Milk price ( $\$$ per $45.2 \mathrm{~kg}$ ) below which delayed replacement is advantageous during at least 1 mo for both culling policies and variations in seasonality and fixed costs.

\begin{tabular}{|c|c|c|c|c|c|c|}
\hline \multirow[b]{2}{*}{ Seasonality $^{1}$} & \multicolumn{3}{|c|}{ Policy A } & \multicolumn{3}{|c|}{ Policy B } \\
\hline & $50 \%$ & $100 \%$ & $200 \%$ & $50 \%$ & $100 \%$ & $200 \%^{3}$ \\
\hline \multicolumn{7}{|l|}{ Fixed cost ${ }^{2}$} \\
\hline 0 & 16.44 & 18.00 & 20.09 & 17.07 & 18.91 & $>25.00$ \\
\hline 458 & 13.78 & 15.04 & 16.93 & 14.43 & 16.73 & $>25.00$ \\
\hline 878 & 11.25 & 12.18 & 13.66 & 12.07 & 17.95 & $>25.00$ \\
\hline 1061 & 10.17 & 10.97 & 12.25 & 11.07 & 17.60 & $>25.00$ \\
\hline
\end{tabular}

${ }^{1}$ Seasonality was calculated as a percentage of the difference between the average performance for the month of the year and the annual average.

${ }^{2}$ Fixed cost per slot per year (\$). Variable costs were reduced by the amount of the fixed cost to obtain approximately equal total costs.

${ }^{3}$ Milk prices up to $\$ 25$ per $45.2 \mathrm{~kg}$ were evaluated.

486 scenarios), varied from just over $\$ 0$ to $\$ 5$ per slot per year. These losses were the opportunity costs of the slots that remained vacant. The largest losses appeared at $50 \%$ seasonality with low heifer prices and high milk prices.

Table 3 shows the effect of fixed cost on the milk price below which it was optimal to delay replacement during at least 1 mo. When fixed costs were set at $\$ 0$ (from $\$ 458$ per slot per year in the default situation), other variable costs $(\$ 183$ per cow per year in the default situation) were set at $\$ 183+\$ 458=\$ 641$. In the default situation, variable labor cost was approximately $\$ 420$ per cow per year. When all labor costs were assumed fixed, total fixed costs were set at $\$ 458+\$ 420=\$ 878$ per slot per year (and variable labor cost was set at $\$ 0$ ). When both labor cost and other variable cost were set at $\$ 0$, total fixed costs were set at $\$ 458+\$ 420+\$ 183=$ $\$ 1061$ per slot per year. Average total costs per slot per year still varied some with changes in fixed cost, seasonality, policy, and milk prices because the remaining variable costs such as feed cost, breeding cost, and heifer cost were different in each situation. When a higher proportion of the total costs were fixed, delayed replacement was in general only advantageous at a lower milk price. However, delayed replacement was always advantageous for policy B with $200 \%$ seasonality for all milk prices that were evaluated $(\leq \$ 25$ per $45.2 \mathrm{~kg})$.

The option to delay replacement also changed the optimal culling decisions for individual cows in some scenarios. When delay in the summer was advantageous, more cows were culled during the summer months. Those cows would be kept longer under an immediate replacement policy. Similarly, some cows that would be culled under an immediate replacement policy in the fall and winter were kept longer when delayed replacement was advantageous.

\section{DISCUSSION}

The option to delay replacement of cows that left the herd to maximize net return per slot per year was a straightforward extension of the earlier formulations of cow replacement models based on DP. The formulation of the delayed replacement option allows the DP algorithm to determine the optimal month to enter heifers, as well as the optimal time of voluntary culling of every cow in the herd. Furthermore, the model user can chose to deliberately enter or not enter heifers in one or more months of the year.

An advantage of DP is that the sequence of optimal decisions for a slot can be calculated without the need to evaluate every possible sequence of decisions. Thus, DP makes the optimization of large sequential decision problems, such as optimal cow replacement, computationally manageable.

The DP algorithm described in this study optimized replacement decisions for individual slots, ignoring the status and performance of cows in other slots. In addition, there was no restriction on the availability of heifers that could be purchased. Consequently, either all vacant slots were filled with entering heifers or all vacant slots were left vacant until at least the next month.

Earlier replacement models (van Arendonk, 1985a; Kristensen, 1987) allowed for the decision to keep the cow but not necessarily to inseminate her at every opportunity, thereby improving the chances of conception and calving in a more favorable season. The DP algorithm in this study was set up such that eligible open cows were always inseminated if found in estrus and within the eligible breeding period. This restriction was chosen because the option to delay replacement might affect both the replacement decisions for slots and the insemination decisions for cows. McCullough and DeLorenzo (1996) found that every insemination opportu- 
nity was almost always used under conditions comparable to the ones in this study.

Annual revenues and costs for the default input data (Table 1) were plausible for typical Florida dairies (de Vries et al., 2003). The increase in the fraction of heifers entering in the fall under the optimal replacement policy, and the seasonality in herd milk production and net returns per month, agreed with DeLorenzo et al. (1992), who also simulated conditions in Florida. The seasonality in days to conception in the current study (not shown) is similar to results reported for Florida by Oseni et al. (2003). Compared with the culling model of DeLorenzo et al. (1992), the current study used updated data on milk production, pregnancy rates, BW, involuntary culling, and prices.

The results showed that it was slightly advantageous to immediately replace cows that were culled in the summer months under current typical cow performance and price conditions in Florida (e.g., $\$ 1400$ heifer price and $\$ 15.50$ milk price with $100 \%$ seasonality). However, realistic changes in the conditions, such as slightly lower milk prices, higher heifer prices, or more seasonality in cow performance made delayed entering of heifers economically advantageous. On the other hand, if more of the costs were assumed fixed instead of variable, for example, labor cost, delayed replacement was less often advantageous.

The benefits of delayed replacement under conditions in Florida result from more cows that have their peak milk production in the cooler winter months. In addition, more open cows in the cooler season will get pregnant earlier in lactation. The advantages of these effects due to delayed entering of heifers then are larger than the opportunity cost incurred because a slot is temporarily vacant. Delayed replacement may also be advantageous when more favorable prices are expected in the future.

Figure 4 showed that a consequence of delayed replacement is that many more heifers are entered in some months than when temporarily vacant slots are filled all at once. As a result of delayed replacement, net returns and the fractions of cows milking and open vary more from month to month throughout the year as well. Such large variations may be undesirable, for example, leading to temporary cash flow problems or not enough milking parlor capacity. Given such constraints at the herd level, optimization of replacement decisions for individual cows requires simultaneous optimization of decisions for all other slots in the herd. A solution to this optimization problem appears unavailable in realistic replacement models (Houben, 1995).

Delayed replacement is less likely to be advantageous when seasonal effects on cow performance are reduced, for example through heat stress abatement methods (cooling). When cow performance and prices are similar throughout the year, the advantage of scheduling the peak milk production and reproduction in the more favorable season through delayed entering of heifers disappears, whereas the opportunity cost of a vacant slot in the summer increases.

The cost of deliberately not entering heifers in June and July, under conditions when immediate replacement was optimal, was the lowest when cow performance was the most seasonal. The immediate opportunity cost of not entering heifers until August was compensated by having more first-lactation cows that had their peak production during the more favorable (cooler) time of the year.

The average net return per slot per year in this study decreased with less seasonality, due to fewer cows producing and getting pregnant in the less favorable cooler months. In practice, the reduction of seasonal effects is primarily due to improvements in cow performance during the warmer months, whereas cow performance during the cooler months is less affected, thus improving the overall cow performance (Bray et al., 1992). Consequently, less seasonality through cooling is typically associated with increased annual net returns (Dhuyvetter et al., 2000).

Genetic improvement in milk production has only a small effect on the optimal replacement policy (Allaire, 1981; van Arendonk, 1985a) and was therefore not included. Genetic improvement can be included in the DP algorithm as shown by van Arendonk (1985a). The effect of genetic improvement on optimal delayed replacement decisions is not clear and needs to be studied further.

No seasonal effects on the probability of involuntary culling were assumed in this study, but some evidence exists that in Florida it is higher in the summer months (Butler and de Vries, 2003). That study also showed that productive life of heifers calving in the summer is shorter than those calving in the winter. A higher probability of involuntary culling in the summer increases the economic benefits of delayed replacement in the summer months.

Prices were kept constant in this study but can easily be made seasonal or otherwise varied over time. DeLorenzo et al. (1992) assumed lower heifer prices in the fall. A higher demand of heifers in the late summer and fall could increase heifer prices at that time of the year. This would make delayed replacement in the summer less advantageous.

Uncertainty in future prices can be incorporated by adding states with different prices and transition probabilities between these states to the model, in the same way as the 15 milk production classes allow for variability in milk production. Furthermore, use of a high inter- 
est rate puts less weight on price estimates for the future.

The user-interface of the model allows for a quick and easy evaluation of farm-specific inputs. The results of various assumptions about cow performance and prices can be easily compared. Delayed replacement is less likely advantageous when fixed costs are a larger portion of the total costs. Therefore, it needs to be decided how variable various costs, such as labor, are. Given the substantial variation in cow performance, revenues, and costs in Florida (de Vries et al., 2003) delayed replacement in the summer is likely to be advantageous for a portion of the Florida producers.

\section{CONCLUSIONS}

A DP algorithm to determine the optimal culling policy of cows was extended with the option to optimally delay, enforce delay, or prohibit delay of entering heifers into vacant slots in the herd. Delayed replacement may be advantageous when returns minus variable cost are low and vary over time, for example when cow performance is seasonal. Delayed replacement was not economically advantageous under typical current conditions in Florida when the cow culling policy was optimal. A nonoptimal culling policy resulted in an advantage of less than $\$ 2$ per slot per year when heifers were not entered in May through July. Realistic lower milk prices, higher heifer prices, and more seasonality in cow performance resulted in not entering heifers in the summer (and spring) months when cow performance was at its lowest level, for both culling policies. Instead, more heifers entered the herd toward the fall at the start of the more favorable (cooler) season. For all price and seasonality scenarios considered, the maximum value of optimal delayed replacement per slot per year was $\$ 19$ for the optimal culling policy and $\$ 88$ for the nonoptimal culling policy. Dairy producers should consider delayed replacement when returns minus variable costs are low and seasonality in cow performance is high.

\section{ACKNOWLEDGMENTS}

The author appreciates the cooperation of John Clay and Crystal Vierhout of Dairy Record Management Systems, Raleigh, NC, in providing access to the Florida DHI test-day records used in this study.

\section{REFERENCES}

Allaire, F. R. 1981. Economic consequences of replacing cows with genetically improved heifers. J. Dairy Sci. 64:1985-1995.
Allison, P. D. 1995. Survival Analysis Using the SAS System: A Practical Guide. BBU Press, Cary, NC.

Bascom, S. S., and A. J. Young. 1998. A summary of reasons why farmers cull cows. J. Dairy Sci. 81:2299-2305.

Beaudeau, F., J. D. van der Ploeg, B. Boileau, H. Seegers, and J. P. T. M. Noordhuizen. 1996. Relationships between culling criteria in dairy herds and farmers' management styles. Prev. Vet. Med. 25:327-342.

Ben-Ari, Y., I. Amir, and S. Sharar. 1983. Operational replacement decision model for dairy herds. J. Dairy Sci. 66:1747-1759.

Bray, D. R., D. K. Beede, R. A. Bucklin, and G. L. Hahn. 1992. Cooling, Shade, and Sprinkling. Chapter 66 in Large Dairy Herd Management, ADSA, Champaign, IL.

Butler, B. L., and A. de Vries. 2003. Seasonality of productive life of dairy cows in Florida and Georgia. J. Dairy Sci. 86(Suppl. 1):54-55. (Abstr.)

de Vries, A., R. Giesy, L. Ely, A. de Araujo, A. Andreasen, B. Broaddus, S. Eubanks, D. Mayo, P. Miller, T. Seawright, and C. Vann. 2003. Dairy Business Analysis Project: 2001 Financial Summary. Univ. Florida Ext. Publ. AN136.

DeLorenzo, M. A., T. H. Spreen, G. R. Bryan, D. K. Beede, and J. A. M. van Arendonk. 1992. Optimizing model: Insemination, replacement, seasonal production, and cash flow. J. Dairy Sci. 75:885-896.

Dhuyvetter, K. C., T. L. Kastens, M. J. Brouk, J. F. Smith, and J. P. Harner, III. 2000. Economics of cooling cows. Pages 56-71 in Proc. Heart of America Dairy Management Conference, St. Joseph, MO.

Dijkhuizen, A. A., and J. Stelwagen. 1988. An economic comparison of four insemination and culling policies in dairy herds, by method of stochastic simulation. Livest. Prod. Sci. 18:239-252.

Houben, E. H. P., R. B. M. Huirne, A. A. Dijkhuizen, and A. R. Kristensen. 1994. Optimal replacement of mastitic cows determined by a hierarchic Markov process. J. Dairy Sci. 77:29752993.

Houben, E. H. P. 1995. Economic optimization of decisions with respect to dairy cow health management. Ph.D. Diss., Wageningen Agric. Univ., The Netherlands.

Jalvingh, A. W., A. A. Dijkhuizen, and J. A. M. van Arendonk. 1992. Dynamic probabilistic modelling of reproduction and replacement management in sow herds. Agric. Syst. 39:133-152.

Jalvingh, A. W., A. A. Dijkhuizen, and J. A. M. van Arendonk. 1994. Optimizing the herd calving pattern by using linear programming and dynamic probabilistic simulation. J. Dairy Sci. 77:1719-1730.

Kennedy, J. O. S., and A. W. Stott. 1993. An adaptive decisionmaking aid for dairy cow replacement. Agric. Syst. 42:25-39.

Kristensen, A. R. 1987. Optimal replacement and ranking of dairy cows determined by a hierarchic Markov process. Livest. Prod. Sci. 16:131-144.

Kristensen, A. R. 1991. Maximization of net revenue per unit of physical output in Markov decision processes. Eur. Rev. Agric. Econ. 18:231-244.

McCullough, D. A. 1992. Effects of model specifications and exogenous variables of a stochastic dynamic insemination and replacement model for dairy cattle. M.S. Thesis, Univ. Florida, Gainesville.

McCullough, D. A., and M. A. DeLorenzo. 1996. Effects of price and management level on optimal replacement and insemination decisions. J. Dairy Sci. 79:242-253.

Milian-Suazo, F., H. N. Erb, and R. D. Smith. 1988. Descriptive epidemiology of culling in dairy cows from 34 herds in New York state. Prev. Vet. Med. 6:243-251.

Monti, G., B.-A. Tenhagen, and W. Heuwieser. 1999. Culling policies in dairy herds. A review. J. Vet. Med. Ser. A. 46:1-11.

National Research Council. 2001. Nutrient Requirements of Dairy Cattle. 7th rev. ed. Natl. Acad. Sci., Washington, DC.

Oseni S., I. Misztal, S. Tsuruta, and R. Rekaya. 2003. Seasonality of days open in US Holsteins. J. Dairy Sci. 86:3718-3725. 
Rogers, G. W., J. A. M. van Arendonk, and B. T. McDaniel. 1988. Influence of production and prices on optimum culling rates and annualized net revenue. J. Dairy Sci. 71:3453-3462.

Smith, B. J. 1971. The dairy cow replacement problem: An application of dynamic programming. Univ. Florida Agric. Exp. Stn Bulletin 745. Gainesville.

Stewart, H. M., E. B. Burnside, J. W. Wilton, and W. C. Pfeiffer. 1977. A dynamic programming approach to culling decisions in commercial dairy herds. J. Dairy Sci. 60:602-617. van Arendonk, J. A. M. 1985a. Studies on the replacement policies in dairy cattle. II. Optimum policy and influence of changes in production and prices. Livest. Prod. Sci. 13:101-121.

van Arendonk, J. A. M. 1985b. A model to estimate the performance, revenues and costs of dairy cows under different production and price situations. Agric. Syst. 16:157-189.

van Arendonk, J. A. M. 1986. Studies on the replacement policies in dairy cattle. IV. Influence of seasonal variation in performance and prices. Livest. Prod. Sci. 14:15-28. 